\title{
Effect of Ascorbic acid Concentration on Electrical Conductivity of reduced Graphene oxide
}

\author{
Kanpichcha Jaroensil, Voranuch Thongpool, and Sumonman Niamlang*
}

\begin{abstract}
The reduction of graphene oxide (GO) by Hummer's methods was investigated using Ascorbic acid. The prepared GO and Ascorbic acid reduced GO (RGO) were haracterized by SEM, XRD, Fourier transform infrared, Raman spectroscopy, ultraviolet-visible spectroscopy and electrical conductivity.
\end{abstract}

Keywords - Graphene oxide; Reduced Graphene oxide; Ascorbic acid; Electrical conductivity.

\section{INTRODUCTION}

$\mathrm{G}$ RAPHENE is a fascinating two dimensional single layered hexagonal lattice of various carbon allotropes with atomic thickness which has been studied extensively in various energy and environmental application. ${ }^{[1]}$ The preparation of graphene was achieved with variousmethod such as electrochemical methods ${ }^{[2]}$,chemical reduction of graphene oxide ${ }^{[3]}$, ion exchange methods ${ }^{[4]}$, hydrothermal reduction methods ${ }^{[5]}$ and sol-gel methods ${ }^{[6][7]}$. Among these, chemical reduction of graphene oxidepresents very easier route for the production of good quality grapheme. However,chemical reduction of graphene oxideemploy hazardous chemicals reducing agents e.g. hydrazine and $\mathrm{NaBH}_{4}$. Recently, environment-friendly chemical agents,such as glutathione ${ }^{[8]}$, sugar ${ }^{[9]}$, clove ${ }^{[10]}$ and wild carrot root ${ }^{[11]}$ have been reported to reduced grapheme oxide.

Ascorbic acid is anaturally occurring organic compound with antioxidant properties. It is a white solid, but impure samples can appear yellowish. It dissolves well in water to give mildly acidic solutions.

In this paper, The graphene oxide (GO) was produced using simplified Hummer's methods. Ascorbic acid was used as a reducing agent.The reduction graphene oxide(RGO) was characterized by Scanning electron microscopy(SEM),Xray diffraction(XRD), Fourier transform infrared(FTIR),UVVISSpectrophotometer(UV-VIS), Ramanspectroscopy

(Raman).The electrical conductivity of RGO was also reported.

Kanpichcha Jaroensil is a Master Student, Rajamangala University of Technology Thanyaburi, Thailand.

Dr. Sumonman Niamlang*, Faculty of Engineering, Rajamangala University of Technology Thanyaburi, Thailand.

\section{MATERIAL}

Graphite flakes (purity 99\%) were obtained from Loba Chemie, Kolkata, India. Concentrated sulphuric acid (98\%), hydrogen peroxide (H2O2, 30\%) and concentrated hydrochloric acid $(30 \%)$ were purchased from Merck, India and were used as received. Potassium permanganate $\left(\mathrm{KMnO}_{4}\right)$ was obtained from Analytical Rasayan, India and was used as an oxidizing agent.

\section{PREPARATION OF GRAPHENE OXIDE}

GO was synthesized from graphite by a modified Hummer's method ${ }^{[12]}$. The $5 \mathrm{~g}$ of graphite was mixed with $100 \mathrm{~mL}$ of $\mathrm{H}_{2} \mathrm{SO}_{4}$ in an at temperature $0^{\circ} \mathrm{C}$ for $15 \mathrm{~min}$. While maintaining magnetic vigorous stirring, a certain amount of $\mathrm{KMnO}_{4}(15 \mathrm{~g})$ was added to the suspension. The mixture was stirred for $15 \mathrm{~min}$ at room temperature and $400 \mathrm{~mL}$ of $\mathrm{H}_{2} \mathrm{O}$ was then slowly added to the mixture. The synthesized GO was obtained. The reaction temperature was rapidly increased to $98^{\circ} \mathrm{C}$, and the color changed to light brown. Finally, the mixture was rinsed and filtration with deionized water for several time until $\mathrm{pH}$ equal to 7 . Synthesized GO was dried in oven at $60{ }^{\circ} \mathrm{C}$ for $24 \mathrm{hr}$.

\section{REDUCTION OF GRAPHENE OXIDE BY ASCORBIC ACID}

To reduce GO, $0.30 \mathrm{~g}$ of $\mathrm{GO}$ was dispersed in $100 \mathrm{ml}$ of water by sonication for $30 \mathrm{~min}$. To study the effect of ascorbic acid on electrical conductivity of RGO, The various amount of ascorbic acid was added into the solution; 100,300 and $500 \mathrm{mg}$ for $2 \mathrm{hr}$. After reduction reaction., RGO solution were filtration and rinsed with water for several time to remove the unwanted materials. The $\mathrm{RGO}$ were dried in an air oven at $60^{\circ} \mathrm{C}$ and stored in the air light container for further investigated.

\section{v. ELECTRICAL PROPERTIES MEASUREMENT}

The sheet resistivity of the top emitter layer is very easy to measure experimentally using a "four point probe". A current is passed through the outer probes and induces a voltage in the inner voltage probes. The junction between the $n$ and $p$-type materials behaves as an insulating layer and the cell must be kept in the dark. A schematic diagram of the test circuit for measuring bar specimen resistivity by the FPP method is presented in Figure 1 A constant current, I, was applied to the bar specimen through two outside probes with the help of a DC power source, and then the steady voltage across the other 
inside two probes, $\mathrm{V}$ was determined. According to the FPP method theory, for a circle specimen of finite thickness, $w$, the resistivity, $\rho$, is calculated as

$$
\rho=\frac{\Pi}{\ln 2} \mathrm{w}\left(\frac{V}{I}\right)
$$

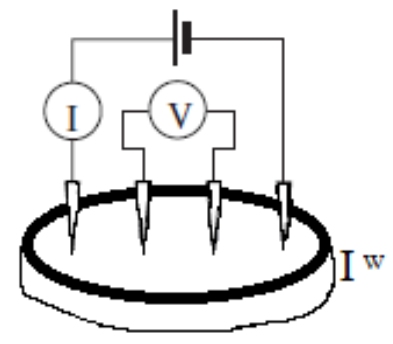

Fig. 1 Schematic diagram of test circuit for measuring specimen resistivity with the four-point probe method

\section{RESULTS AND DISCUSSION}

\section{A. The morphology of Graphite, $G O$ and Ascorbic acid-RGO}
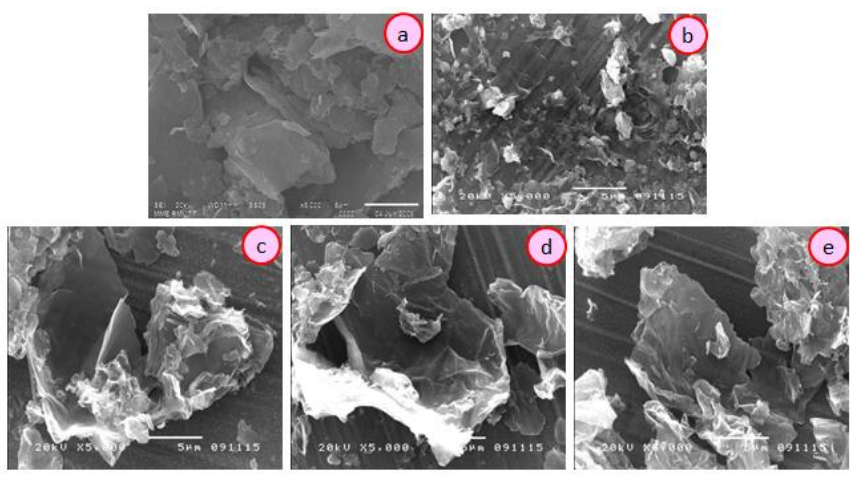

Fig. 2 SEM images of (a) Graphite (b) GO

(c) Ascorbic acid (100 mg) RGO (d) Ascorbic acid (300 mg) RGO (e) Ascorbic acid (500 mg) RGO

Figure 2(a) showed a multilayered, wavy, folded flakes graphite. Figure 2(b) showed GO, GO were smooth with folded shapes at the edges, thin sheet and transparent and Reduced GO by 100,300 and $500 \mathrm{mg}$ of ascorbic acid respectively images revealed that the reduced GO material consisted of several layers stacked on top of one another like sheets of paper, with silky, wrinkled, thin morphology were showed in Figure2 (c, d and e) respectively.

\section{B. The crystal structures}

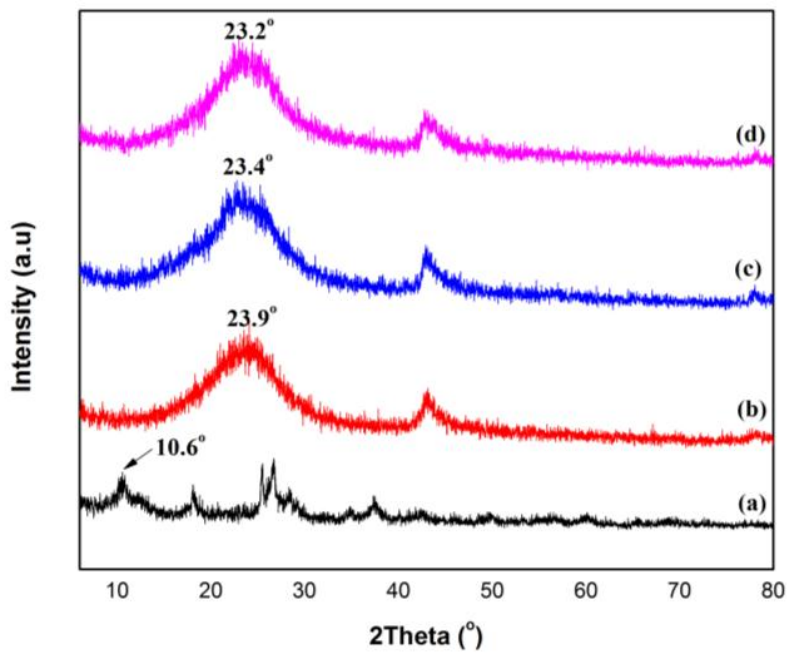

Fig. 3 XRD pattern of (a) GO (b) Ascorbic acid (100 mg) RGO (c) Ascorbic acid (300 mg) RGO (d) Ascorbic acid (500 mg) RGO

Suman Thakur et all,reported XRD patterns of graphite, GO, RGO are Pristine graphite exhibits a basal reflection peak at $2 \theta=26.6^{\circ}$. Upon oxidation of pristine graphite, the reflection peak shifts to the lower angle at $2 \theta=9.75^{\circ},(\mathrm{d}$ spacing $=0.906 \mathrm{~nm}$ ). The increase in $\mathrm{d}$ spacing is due to the intercalation of water molecules and the formation of oxygen containing functional groups between the layers of the graphite. In contrast to GO, all RGO have a broad peak centered at $2 \theta=25^{\circ}{ }^{[7]}$. The crystal structures of GO and Ascorbic acid-RGO were confirmed using XRD analysis. Figure 3 shows the XRD spectrum of GO. The characteristic peak of GO appeared at $2 \theta=10.6^{\circ}$ which curres. The Ascorbic acid-RGO 100,300 and $500 \mathrm{mg}$ respectively shows peaks at $2 \theta$ $=23.9^{\circ}, 23.4^{\circ}$ and $23.2^{\circ}$.

\section{FTIR Characterization of GO and Ascorbic acid-RGO}

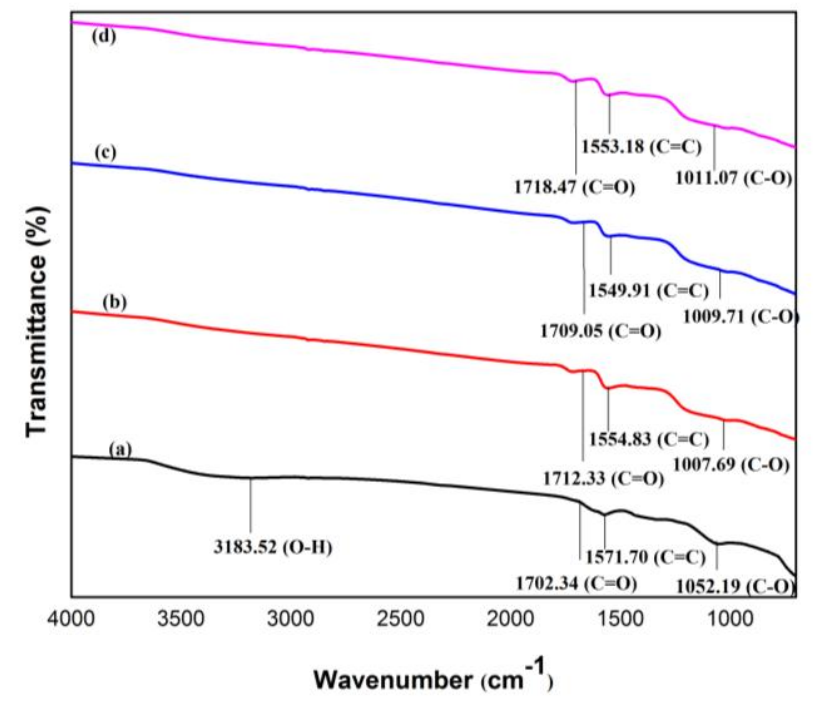

Fig. 4 FTIR spectrum of (a) GO (b) Ascorbic acid (100 mg) RGO (c) Ascorbic acid (300 mg) RGO (d) Ascorbic acid (500 mg) RGO

Fourier transform infrared (FTIR) study was performed over the wavenumber, range of $4000-400 \mathrm{~cm}^{-1}$. Figure 4 shows FTIR spectra of the GO. Strong absorption peaks were 
observed at $3183.52 \mathrm{~cm}^{-1}$. Due to the vibration and deformation bands of $\mathrm{O}-\mathrm{H}$ and $\mathrm{C}=\mathrm{O}$ stretching vibrations from carbonyl groups $\mathrm{C}=\mathrm{C}$ configurable vibrations from the aromatics $\mathrm{C}-\mathrm{OH}$ stretching vibrations $\mathrm{C}-\mathrm{O}$ vibrations from epoxy groups, and $\mathrm{C}-\mathrm{O}$ vibrations from alkoxy groups respectively. However, most of the peaks related to the oxygen-containing functional groups were removed in the FTIR spectrum of Ascorbic acid (100 mg) RGO Ascorbic acid (300 mg) RGO and Ascorbic acid (500 mg) RGO suggesting that these oxygen containing functional groups were removed in the process of reduction using Ascorbic acid. Interestingly, some new peaks also appeared in the spectra of Ascorbic acidRGO at $1007-1012 \mathrm{~cm}^{-1}, 1548-1560 \mathrm{~cm}^{-1}$ and $1700-1720 \mathrm{~cm}^{-1}$ attributed to the skeletal vibration of the graphene sheets. In the Ascorbic acid-RGO sample the intensities of the bands associated with the oxygen functional groups were significantly decreased.

\section{Raman Characterization of $G O$ and Ascorbic acid-RGO}

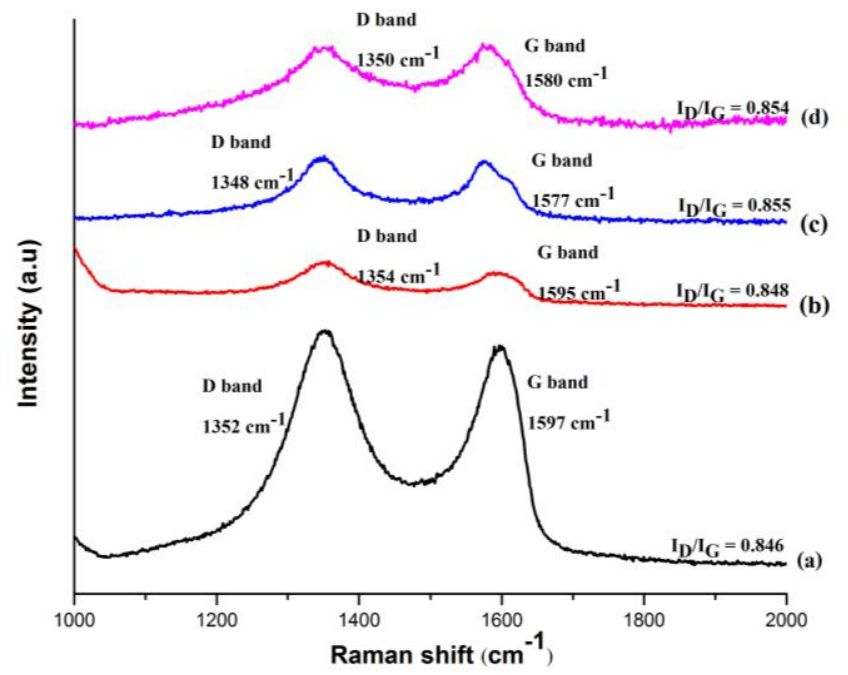

Fig. 5 Raman spectrum of (a) GO (b) Ascorbic acid (100 mg) RGO (c) Ascorbic acid (300 mg) RGO (d) Ascorbic acid (500 mg) RGO

Raman spectra of the GO and Ascorbic acid-RGO show the existence of D-band and G-bands in Figure 5 The D-band is attributed to of $\mathrm{sp}^{3}$ carbon atoms of disordered graphite, and G-band is related to the in plane vibration of $\mathrm{sp}^{2}$ carbon atoms. The G-band of the GO located at $1597 \mathrm{~cm}^{-1}$, ascorbic acid shifted to1575-1595 $\mathrm{cm}^{-1}$ for the RGO, which is close to the value of the pristine graphite and confirms the efficient reduction of GO. However, the G-band of RGO showed a longer wave number $1345-1355 \mathrm{~cm}^{-1}$, compared to that of raw graphite $1352 \mathrm{~cm}^{-1}$, possibly due to the interaction between the ascorbic acid and microorganisms.

\section{E. $U V$-Vis spectrum of $G O$ and Ascorbic acid-RGO}

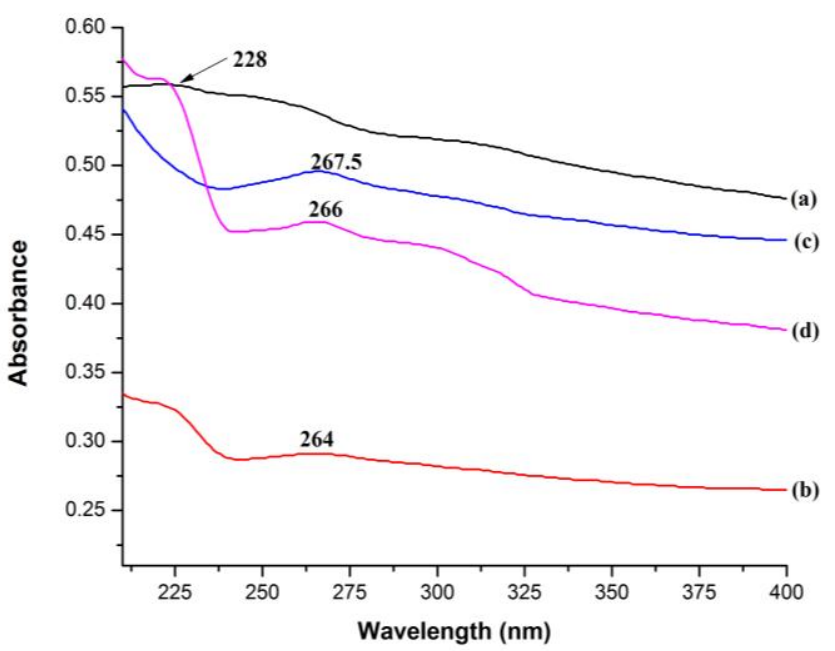

Fig. 6 UV-VIS spectrum of (a) GO (b) Ascorbic acid (100 mg) RGO (c) Ascorbic acid (300 mg) RGO (d) Ascorbic acid (500 mg) RGO

The UV-vis spectrum of GO (Figure 6) exhibits a peak at $230 \mathrm{~nm}$ and a shoulder peak at $300 \mathrm{~nm}$. The peak at $228 \mathrm{~nm}$ can be corresponded to $\pi-\pi^{*}$ transitions of aromatic $\mathrm{C}=\mathrm{C}$, while the shoulder peak originates from $\mathrm{n}-\pi^{*}$ transition of the $\mathrm{C}=\mathrm{O}$ bonds. The absorptions spectrum of Ascorbic acid-RGO samples exhibit peak around 264,266 and $267.5 \mathrm{~nm}$. This shift in the absorption spectrum from 230 to $270 \mathrm{~nm}$ points towards the restoration of $\mathrm{sp}^{2}$ hybridized carbon network due to removal of the oxygen bearing functional groups.

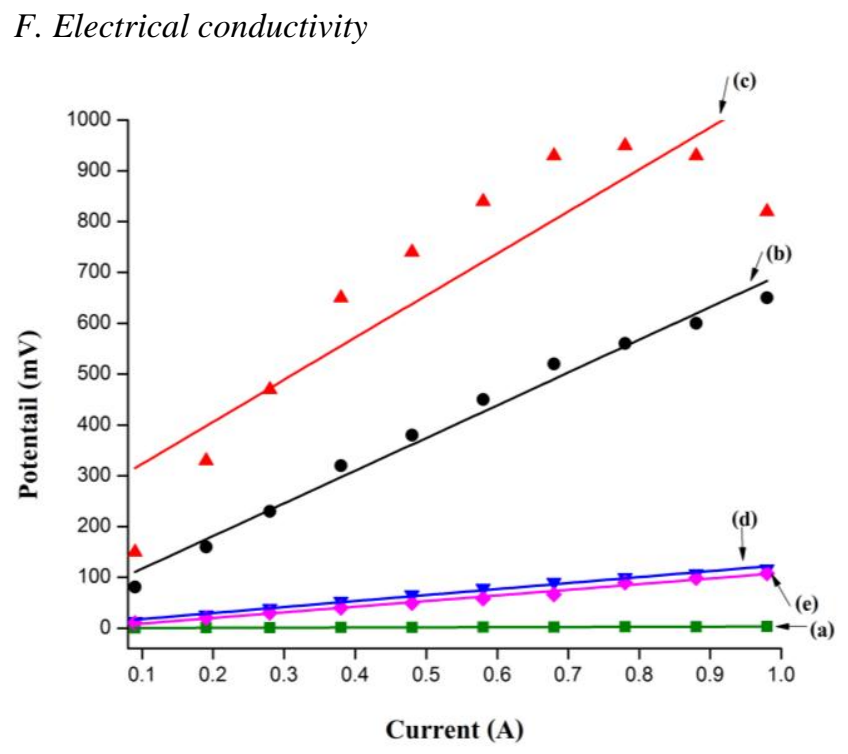

Fig. 7 Electrical conductivity of (a) Graphite (b) GO (c) Ascorbic acid (100 mg) RGO (d) Ascorbic acid (300 mg) RGO (e) Ascorbic acid (500 mg) RGO

The conductivity values obtained from $\mathrm{I}-\mathrm{V}$ curves were comparable with benzyl alcohol reduced GO (conductivity values $4600 \mathrm{Sm}^{-1}$ ) as well as vitamin $\mathrm{C}$ reduced $\mathrm{GO}$ (conductivity values between 2690 and $7700 \mathrm{Sm}^{-1}$ ) ${ }^{[7]}$. Figure 7 shows the conductivity values obtained from I-V curves. The analysis of the conductivity data show in Table 1. Graphite

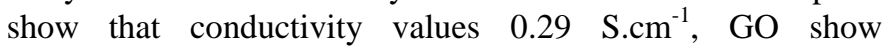


conductivity values at $1.50 \times 10^{-3} \mathrm{~S}^{-\mathrm{cm}^{-1}}$, ascorbic acid $(100 \mathrm{mg})$ RGO show conductivity values at $9.01 \times 10^{-4} \mathrm{~S}_{\mathrm{cm}} \mathrm{cm}^{-1}$, ascorbic acid (300 mg) RGO show conductivity values at $6.32 \times 10^{-3} \mathrm{~S}^{-\mathrm{cm}^{-1}}$ and ascorbic acid (500 mg) RGO show conductivity values at $6.72 \times 10^{-3} \mathrm{~S} . \mathrm{cm}^{-1}$.

TABLE I

THE ANALYSIS OF ELECTRICAL CONDUCTIVITY DATA

\begin{tabular}{|l|l|l|l|}
\hline Sample & $\begin{array}{l}\text { Thickness } \\
(\mathrm{cm})\end{array}$ & $\begin{array}{l}\text { Resistivity } \\
(\Omega . \mathrm{cm})\end{array}$ & $\begin{array}{l}\text { Conductivity } \\
\left({\left.\mathrm{S} . \mathrm{cm}^{-1}\right)}^{-1}\right.\end{array}$ \\
\hline $\begin{array}{l}\text { Graphite } \\
\text { Graphene }\end{array}$ & 0.27 & 3.48 & 0.29 \\
$\begin{array}{l}\text { Ascorbic acid } \\
(100 \mathrm{mg}) \text { RGO }\end{array}$ & 0.25 & 665.65 & $1.50 \times 10^{-3}$ \\
$\begin{array}{l}\text { Ascorbic acid } \\
(300 \mathrm{mg}) \text { RGO }\end{array}$ & 0.35 & 1109.58 & $9.01 \times 10^{-4}$ \\
$\begin{array}{l}\text { Ascorbic acid } \\
(500 \mathrm{mg}) \text { RGO }\end{array}$ & 0.35 & 158.23 & $6.32 \times 10^{-3}$ \\
\hline
\end{tabular}

\section{CONCLUSION}

Demonstrated that the studied ascorbic acid concentration have tremendous potential to be used as reducing agents for the reduction of GO with an environmental benign synthetic. The most important advantages of the ascorbic acid are their abundance in nature, cost effectiveness and easy. The values of high electrical conductivity are acceptable. Thus this green method can be used for large scale production of RGO.

\section{REFERENCES}

[1] Xu-Yuan Peng, Xiao-Xia Liu, Dermot Diamond, King Tong Lau.Synthesis of electrochemically-reduced graphene oxide film with controllable size and thickness and its use in supercapacitor. Nature Nanotech 2008; 3:563-8

[2] Sungjin Park, Rodney S. Ruoff. Chemical methods for the production of graphenes. Nature Nanotechnology 4, 217 - 224 (2009) http://dx.doi.org/10.1038/nnano.2009.58

[3] Shive Murat Singh Chauhan, Sweta Mishra. Use of Graphite Oxide and Graphene Oxide as Catalysts in the Synthesis of Dipyrromethane and Calix pyrrole. Molecules 2011, 16, 7256-7266 http://dx.doi.org/10.3390/molecules16097256

[4] Ji-Lei Shi, Wen-Cheng Du, Ya-Xia Yin, Yu-Guo Guo, Li-Jun Wan.Hydrothermal reduction of three-dimensional graphene oxide for binder-free flexible supercapacitors. Electronic Supplementary Material (ESI) for Journal of Materials Chemistry A. This journal is () The Royal Society of Chemistry 2014

[5] Ravi Kant Upadhyay, Navneet Soin , Gourav Bhattacharya. Grape extract assisted green synthesis of reduced graphene oxide for water treatment application. Materials Letters 160 (2015) 355-358

http://dx.doi.org/10.1016/j.matlet.2015.07.144 